\title{
Prognostic value of brain natriuretic peptide in patients with heart failure and reserved left ventricular systolic function
}

\author{
HUI GONG ${ }^{1}, \mathrm{XIN}_{\text {WANG }}^{2}$, YI LING ${ }^{2}$ YIJUN SHI $^{2}$ and HAIMING SHI ${ }^{1}$ \\ ${ }^{1}$ Division of Cardiology, Department of Medicine, Huashan Hospital of Fudan University, Shanghai 200040; \\ ${ }^{2}$ Division of Cardiology, Department of Medicine, Jinshan Hospital of Fudan University, Shanghai 201508, P.R. China
}

Received November 6, 2013; Accepted March 11, 2014

DOI: $10.3892 /$ etm.2014.1635

\begin{abstract}
Brain natriuretic peptide (BNP) is used as a prognostic biomarker for patients with heart failure (HF) in clinical practice, however, the correlation between BNP levels and the prognosis of HF in patients with reserved left ventricular systolic function (RLVSF) is not clear. Thus, the aim of the present study was to evaluate the added value of BNP in the prognosis of HF patients with RLVSF. Inpatients with cardiovascular disease (mean age, 65.7 years; male, 790; female, 625) admitted to the Division of Cardiology at Jinshan Hospital of Fudan University (Shanghai, China) between June 2006 and December 2009 underwent follow-up examinations. Plasma BNP levels were analyzed and measurements of the left ventricular ejection fraction (LVEF) were performed by echocardiography. Evaluations of the patients with HF were performed according to the New York Heart Association (NYHA) classification system. The duration of the follow-up period ranged between 21 and 63 months (average duration, 35.8 months) and key events included cardiovascular mortality, readmission due to cardiovascular disease or mortality due to other reasons. Survival times decreased with increasing BNP levels in all the follow-up patients (Spearman's $\rho,-0.1877$; $\mathrm{P}<0.0001$ ). Among the 1,415 patients, 1,312 underwent echocardiographic detection. A total of 395 patients with NYHA classes II-IV and a LVEF $\geq 45 \%$ were selected. The incidence of compound endpoint events was significantly higher in the patients that had BNP levels of $>100 \mathrm{pg} / \mathrm{ml}$ when compared with the patients that had BNP levels of $\leq 100 \mathrm{pg} / \mathrm{ml}$ (37.07 vs. $23.93 \%$; relative risk, 1.55$)$; consequently the survival times were significantly reduced $(\mathrm{P}=0.0039)$. A negative correlation was identified between the BNP levels and the survival times in these patients (Spearman's $\rho,-0.1738 ; \mathrm{P}=0.0005$ ). These results indicated that the levels of BNP may be used
\end{abstract}

Correspondence to: Dr Haiming Shi, Division of Cardiology, Department of Medicine, Huashan Hospital of Fudan University, 12 Urumqi Road, Shanghai 200040, P.R. China

E-mail: hgxwen@126.com

Key words: brain natriuretic peptide, heart failure, left ventricular systolic function, prognosis to predict the prognosis of patients with cardiovascular disease. The prognoses of patients with higher BNP levels were worse compared with the patients with lower BNP levels. Furthermore, significant correlations were confirmed in the HF patients with RLVSF.

\section{Introduction}

Brain natriuretic peptide (BNP) is a 32-amino acid polypeptide containing a 17-amino acid ring structure common to all natriuretic peptides (1). BNP is stored in human cardiac tissue as BNP-32 with a lesser amount of the precursor preproBNP, and in the circulating plasma as BNP-32 and the N-terminal proBNP (NT-proBNP) (2). BNP is a cardiac neurohormone that is secreted into the plasma from the ventricles in response to ventricular volume expansion and pressure overload. BNP levels are useful for the diagnosis of left ventricular (LV) systolic and diastolic dysfunction and have been shown to correlate with the severity and prognosis (3). BNP provides an easy method for the early detection of heart failure (HF), and for assessing the severity of HF and the effectiveness of treatment (4).

A previous study identified that BNP and NT-proBNP are the prognostic importance in patients with $\mathrm{HF}$ and with acute coronary syndromes, and both markers have been shown to be strong predictors of morbidity and mortality (5).

Diastolic wall stress has been shown to exhibit a stronger correlation with the levels of NT-proBNP than that of systolic wall stress (6). The estimation of BNP values may be accepted as a fast and reliable blood test in the diagnosis of asymptomatic diastolic dysfunction in patients with hypertension, diabetes and hypertrophic cardiomyopathy (HCM) (7-9). Measurement of BNP levels, which is simple and noninvasive, can be easily and rapidly conducted in emergency departments to guide therapy, follow the response to therapy and predict the exercise capacity of patients (10). However, the role of BNP as a predictor of morbidity and mortality in patients with diastolic dysfunction is unknown. In 2011, a small sample size study (11) hypothesized that the increase in BNP levels over time directly reflected LV diastolic dysfunction and impairment of exercise tolerance. HF patients with reserved left ventricular systolic function (RLVSF) are considered to be patients with diastolic dysfunction. Therefore, the present study was conducted to evaluate the effect of BNP levels on the survival times of HF patients with RLVSF. 


\section{Patients and methods}

Study subjects and procedures. This was an observational study. Consecutive inpatients with cardiovascular disease, admitted to the Division of Cardiology at Jinshan Hospital of Fudan University (Shanghai, China) between June 2006 and December 2009, underwent follow-up examinations. The Ethics Committee of Jinshan Hospital approved the study protocol and written informed consent was obtained from each patient. The patients were classified according to the initial BNP cutoff point of $100 \mathrm{pg} / \mathrm{ml}$. LV systolic dysfunction was defined by an ejection fraction of $<45 \%$, while systolic function was considered to be normal when the left ventricular ejection fraction (LVEF) was $\geq 45 \%$. Evaluations of the patients with HF were performed using the New York Heart Association (NYHA) classification system. HF was defined as NYHA classes II, III or IV (12). Key events included cardiovascular mortality, readmission due to cardiovascular disease or mortality due to any other reasons.

Measurement of plasma BNP concentration. Blood samples for the analysis of plasma BNP levels were collected at the time of admission and were obtained from the antecubital vein. BNP levels were analyzed using a Triage ${ }^{\circledR}$ BNP test (Biosite Diagnostics, Inc., San Diego, CA, USA), which is a single-use fluorescence immunoassay device designed to determine the concentration of BNP in EDTA-anticoagulated whole blood or plasma specimens. The specimen was added to the sample port of the test device with a transfer pipette that is designed to deliver the appropriate amount of specimen $(250 \mu \mathrm{l})$ to the test device. Following the addition of the specimen, the device was inserted into the Triage ${ }^{\circledR}$ MeterPro (Biosite Diagnostics, Inc.). The MeterPro was programmed to automatically perform the BNP analysis following the reaction of the sample with the reagents within the BNP device. The reaction and analysis process occurred over $\sim 15 \mathrm{~min}$. BNP analysis was based on the amount of fluorescence that the MeterPro detected within a measurement zone on the device. A greater amount of fluorescence detected by the MeterPro indicated a higher BNP concentration in the specimen.

Echocardiography. M-mode and two-dimensional images, as well as spectral and color flow Doppler recordings, were obtained by Vivid 7 ultrasound (GE Healthcare, Andover, MA, USA) with Vivid 7 ultrasound operating at 2.0 to $3.5 \mathrm{MHz}$. The LVEF was calculated from the four-chamber view images using the formula of Simpson's rule.

Statistical analysis. Baseline characteristics of the patients are presented as percentages for dichotomous variables and medians with interquartile ranges for continuous variables such as age. The baseline characteristics were compared between the groups using the Wilcoxon rank-sum test for continuous variables and the $\chi^{2}$ test for discrete variables. Survival curves were generated by Kaplan-Meier estimates and differences in the survival rates were compared between groups using the log-rank test. The incidence of endpoint events was compared between the groups by means of relative risk. Spearman's correlation was used to analyze the correlation between the levels of BNP and the survival times of the patients. BNP levels were evaluated by receiver operating characteristic (ROC) and area under the curve (AUC) analyses for predicting the incidence of clinical compound endpoints. To determine the optimal value of specificity and sensitivity, the closest value to the best specificity and sensitivity point on the ROC curve was identified. $\mathrm{P}<0.05$ was considered to indicate a statistically significant difference.

\section{Results}

Patient characteristics. The study population consisted of 1,415 patients. The mean age was 65.7 years and almost half the patients were male $(790 / 1,415,55.8 \%)$. The duration of the follow-up period ranged between 21 and 63 months (average duration, 35.8 months). Characteristics of the overall patient population are shown in Table I. Risk factors of the patients included hypertension $(953 / 1415,67.35 \%)$, diabetes $(291 / 1415$, $32.33 \%)$, dyslipidemia $(622 / 1415,43.96 \%)$, renal dysfunction $(115 / 1415,8.13 \%$; serum creatinine $>84 \mu \mathrm{mol} / 1$ in females; serum creatinine $>104 \mu \mathrm{mol} / 1$ in males), myocardial infarction $(190 / 1415,13.53 \%)$ and intervention with medication, including $\beta$-blockers, calcium antagonists, diuretics, nitrates, antiplatelet agents, statins, angiotensin converting enzyme inhibitors and angiotensin receptor blockers. The numbers of patients with BNP levels of $\leq 100$ and $>100 \mathrm{pg} / \mathrm{ml}$ were 900 and 515, respectively. A total of 336 endpoint events occurred, including 143 and 193 in the two BNP groups, respectively. Among the 1,415 patients, 1,312 underwent echocardiographic detection at the same time as admission, including $395(30.11 \%)$ patients with NYHA classes II-IV and a LVEF of $\geq 45 \%$ and $123(9.38 \%)$ patients with systolic dysfunction. The incidence of compound endpoint events was significantly higher in the $\mathrm{BNP}>100 \mathrm{pg} / \mathrm{ml}$ group than in the BNP $\leq 100 \mathrm{pg} / \mathrm{ml}$ group $(86 / 232,37.07$ vs. $39 / 163,23.93 \%$; relative risk=1.55) in 395 patients with NYHA classes II-IV and a LVEF of $\geq 45 \%$.

Survival curves. Kaplan-Meier survival curves of all the patients and specifically the HF patients with RLVSF, according to the BNP levels, are shown in Figs. 1 and 2. The survival curves were constructed in the two groups to predict the survival times of the patients. Survival times were longer in the $\mathrm{BNP} \leq 100 \mathrm{pg} / \mathrm{ml}$ group when compared with the BNP $>100 \mathrm{pg} / \mathrm{ml}$ group and statistically significant differences were observed $\left(\mathrm{P}<0.0001, \chi^{2}=94.11\right.$ and $\mathrm{P}=0.0039, \chi^{2}=8.33$, for all patients and the HF patients with RLVSF, respectively).

Correlation analysis. Spearman correlation analysis demonstrated that the survival times decreased as the BNP levels increased (Spearman's $\rho,-0.1877 ; \mathrm{P}=0.0000$ ). A negative correlation between the $\log \mathrm{BNP}$ levels and the survival times is shown in Fig. 3. A negative correlation was also observed in the $395 \mathrm{HF}$ patients with RLVSF (Spearman's $\rho,-0.1738$; $\mathrm{P}=0.0005)$. A scatter plot demonstrating the correlation between the $\log$ BNP levels and the survival times of the HF patients with RLVSF is shown in Fig. 4.

BNP levels as a predictor for clinical endpoints. The predictive utility of plasma BNP levels in all the patients for determining compound clinical endpoints was calculated with ROC analysis. Plasma BNP levels has diagnostic value in the incidence 
Table I. Baseline clinical characteristics according to the levels of BNP.

\begin{tabular}{|c|c|c|c|}
\hline Characteristics & $\begin{array}{l}\text { Patients with BNP } \\
\leq 100 \mathrm{pg} / \mathrm{ml}(\mathrm{n}=900)\end{array}$ & $\begin{array}{c}\text { Patients with BNP } \\
>100 \mathrm{pg} / \mathrm{ml}(\mathrm{n}=515)\end{array}$ & P-value \\
\hline Age, years (range) & $63(50.0-76.0)$ & $70(56.4-83.6)$ & $<0.05$ \\
\hline Male gender, n (\%) & $513 / 900(57.00)$ & $277 / 515(53.79)$ & 0.242 \\
\hline Mortality, n (\%) & $7(0.77)$ & $24(4.66)$ & $<0.05$ \\
\hline Readmission, $\mathrm{n}(\%)$ & $136(15.11)$ & $169(32.82)$ & $<0.05$ \\
\hline Key events, n (\%) & $143(15.89)$ & $193(37.47)$ & $<0.05$ \\
\hline Systolic dysfunction, n (\%) & $18 / 841(2.14)$ & $105 / 470(22.34)$ & $<0.05$ \\
\hline Non-systolic dysfunction, n (\%) & $163 / 841(19.38)$ & $232 / 470(49.36)$ & $<0.05$ \\
\hline Hypertension, n (\%) & $638(70.89)$ & $315(61.16)$ & $<0.05$ \\
\hline Diabetes, n (\%) & $176(19.55)$ & $115(22.33)$ & 0.214 \\
\hline Dyslipidemia, n (\%) & $477(53.00)$ & $145(28.15)$ & $<0.05$ \\
\hline Renal dysfunction, n (\%) & $31(3.44)$ & $84(16.31)$ & $<0.05$ \\
\hline Myocardial infarction, n (\%) & $96(10.67)$ & $94(18.25)$ & $<0.05$ \\
\hline \multicolumn{4}{|l|}{ Medication, n (\%) } \\
\hline$\beta$-blockers & $480(53.33)$ & $250(48.54)$ & 0.083 \\
\hline Calcium antagonists & $413(45.89)$ & $186(36.12)$ & $<0.05$ \\
\hline Diuretics & $230(25.56)$ & $378(73.40)$ & $<0.05$ \\
\hline Nitrates & $386(42.89)$ & $230(44.66)$ & 0.518 \\
\hline Antiplatelet agents & $713(79.22)$ & $379(73.59)$ & 0.015 \\
\hline Statins & $325(36.11)$ & $135(26.21)$ & $<0.05$ \\
\hline ACEIs or ARBs & $638(70.88)$ & $375(72.82)$ & 0.439 \\
\hline ACEIs & $302(33.56)$ & $187(36.31)$ & 0.294 \\
\hline ARBs & $336(37.33)$ & $188(36.50)$ & 0.756 \\
\hline
\end{tabular}

BNP, brain natriuretic peptide; ACEIs, angiotensin converting enzyme inhibitors; ARBs, angiotensin receptor blockers.

Kaplan-Meier survival estimates, by BNP levels

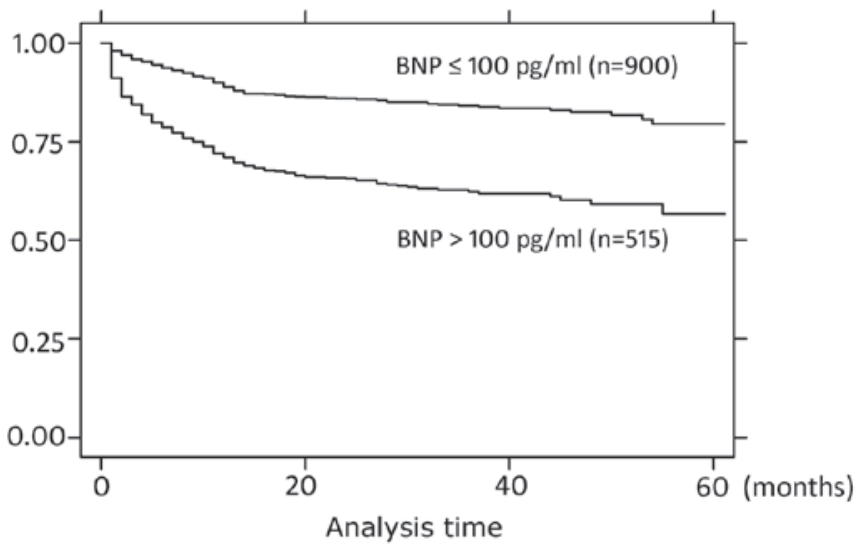

Figure 1. Kaplan-Meier analysis of all the patients with plasma BNP levels higher than $100 \mathrm{pg} / \mathrm{ml}$, and lower than or equal to $100 \mathrm{pg} / \mathrm{ml}(\mathrm{P}<0.0001$; $\left.\chi^{2}=94.11\right)$. BNP, brain natriuretic peptide.

of clinical compound endpoint events in all the patients and in patients with diastolic dysfunction. The AUROC was 0.6752 with a standard error of 0.01698 (95\% confidence interval, 0.64198-0.70835) and the cut-off value for the plasma BNP levels was $100 \mathrm{pg} / \mathrm{ml}$ (sensitivity and specificity, 57.44 and

\section{Kaplan-Meier survival estimates, by BNP levels}

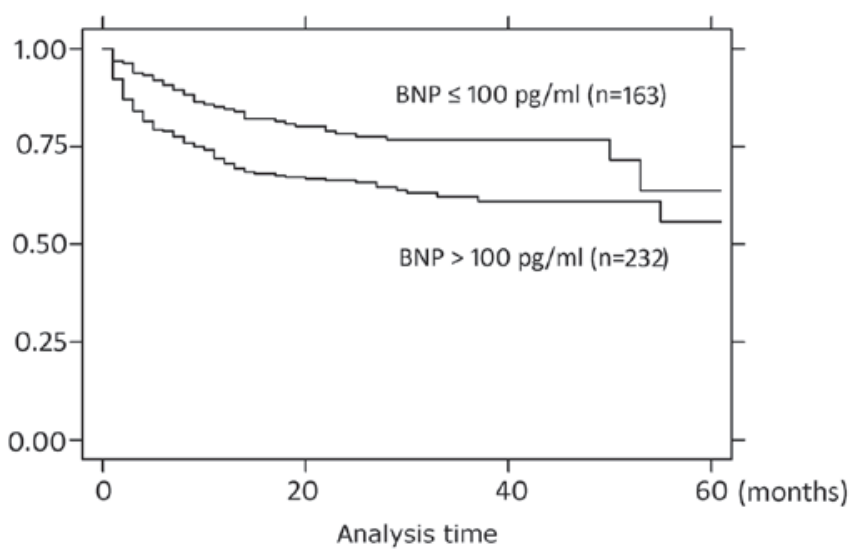

Figure 2. Kaplan-Meier analysis of HF patients with RLVSF with plasma BNP levels higher than $100 \mathrm{pg} / \mathrm{ml}$, and lower than or equal to $100 \mathrm{pg} / \mathrm{ml}$ $\left(\mathrm{P}=0.0039 ; \chi^{2}=8.33\right)$. BNP, brain natriuretic peptide; $\mathrm{HF}$, heart failure; RLVSF, reserved left ventricular systolic function.

$70.16 \%$, respectively; Fig. 5 and Table II). The predictive utility of plasma BNP levels in the HF patients with RLVSF for determining compound clinical endpoints was also calculated with ROC analysis. The AUROC was 0.5877 with a standard 


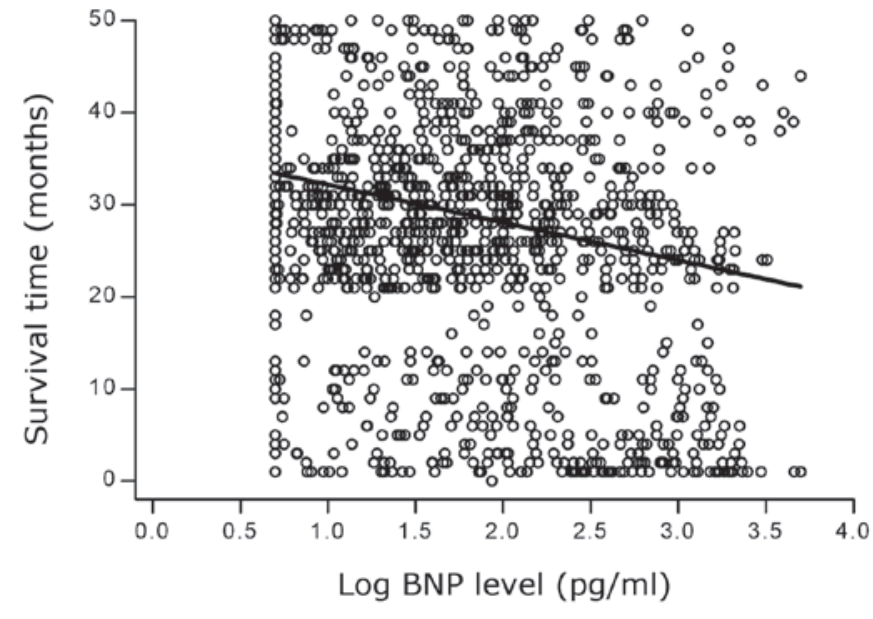

Figure 3. Scatter plot showing the correlation between the $\log \mathrm{BNP}$ levels and the survival times in all the patients. BNP, brain natriuretic peptide.

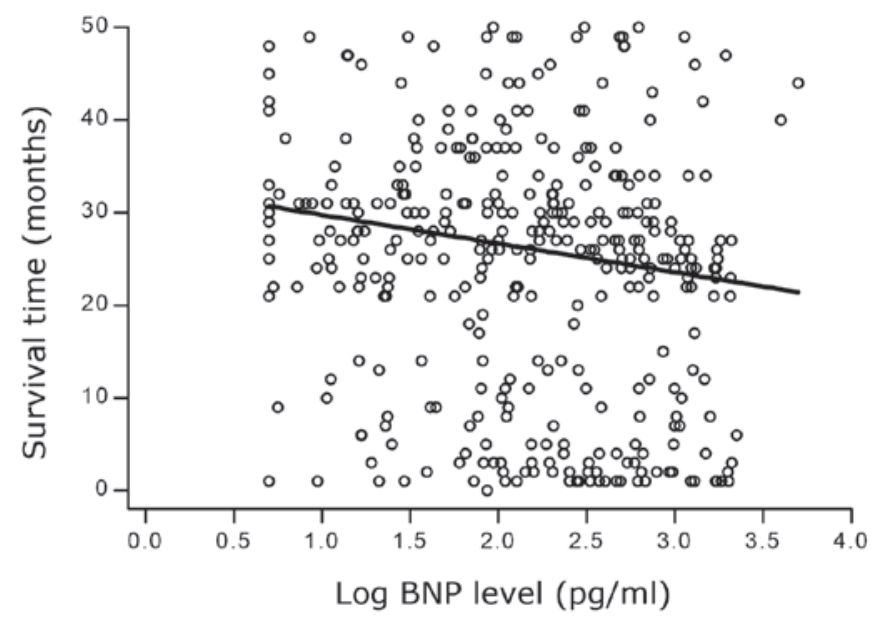

Figure 4. Scatter plot showing the correlation between the $\log$ BNP levels and the survival times in the HF patients with RLVSF. BNP, brain natriuretic peptide; HF, heart failure; RLVSF, reserved left ventricular systolic function.

error of 0.0296 (95\% confidence interval, 0.52965-0.64573) and the cut-off value for the plasma BNP levels was $100 \mathrm{pg} / \mathrm{ml}$ (sensitivity and specificity, 68.8 and $45.93 \%$, respectively; Fig. 6 and Table III).

\section{Discussion}

BNP is a cardiac neurohormone that is secreted into the plasma from the ventricles in response to ventricular volume expansion and pressure overload (3). BNP plasma levels have been shown to be significantly higher in patients with decompensated chronic HF as compared with those in a control group (13). BNP levels provide an easy method for the early detection of $\mathrm{HF}$ and for assessing the severity of $\mathrm{HF}$ and the effectiveness of treatment (14). A number of previous studies have demonstrated that the levels of BNP and NT-proBNP are powerful prognostic markers across a spectrum of acute coronary syndromes (15), from unstable angina and non-ST elevation myocardial infarction to ST elevation myocardial infarction (16-18), as well as in patients with stable angina pectoris $(19,20)$ and even in the absence of significant necrosis (21). BNP and NT-proBNP

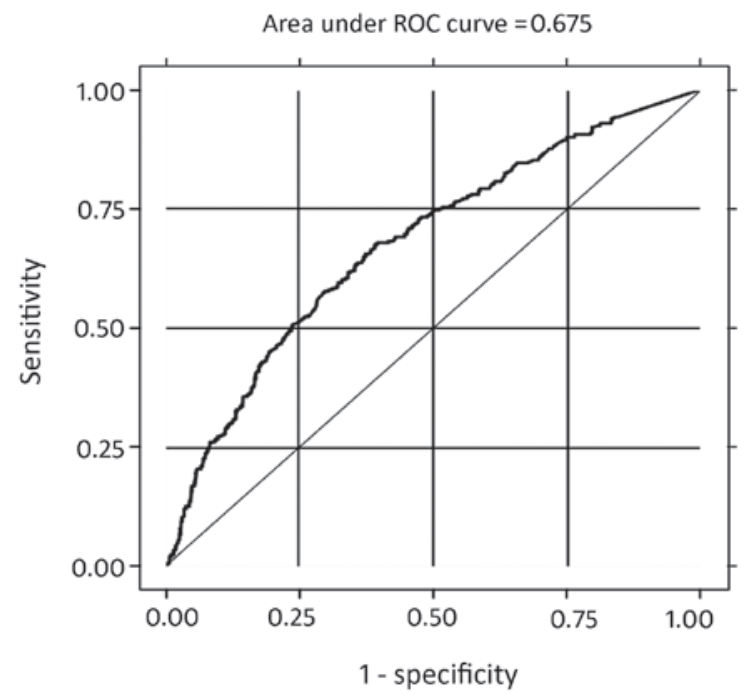

Figure 5. ROC analysis of the $\log \mathrm{BNP}$ levels for determining the incidence of clinical compound endpoint events in all the patients (AUC, 0.6752; standard error, $0.01698 ; 95 \%$ confidence interval, $0.64198-0.70835)$. The cut-off value was determined to be $100 \mathrm{pg} / \mathrm{ml}$ (specificity, 70.16\%; sensitivity, 57.44\%). ROC, receiver operating characteristic; BNP, brain natriuretic peptide; AUC, area under curve.

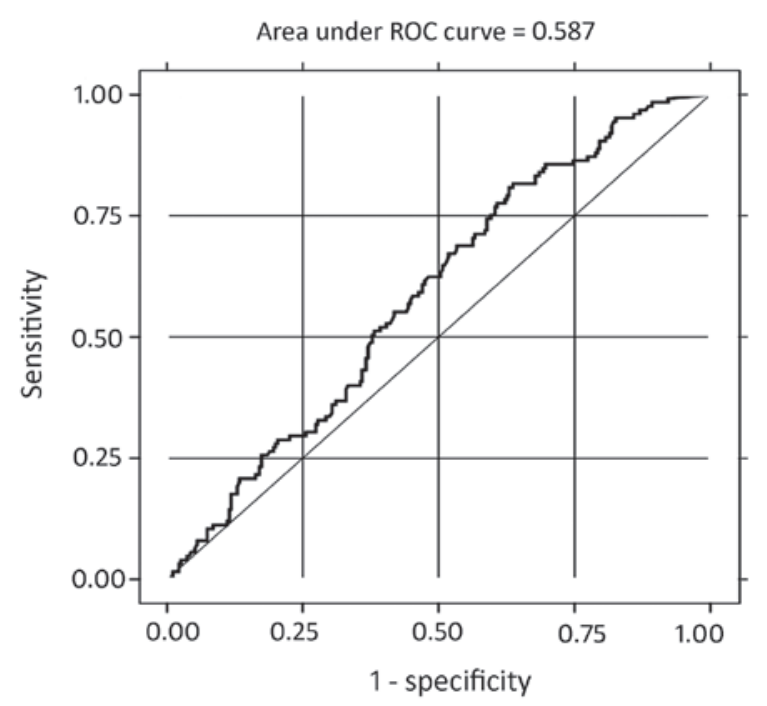

Figure 6. ROC analysis of the $\log \mathrm{BNP}$ levels for determining the incidence of clinical compound endpoint events in patients with diastolic dysfunction (AUC, 0.5877; standard error, 0.0296; 95\% confidence interval, 0.52965-0.64573). The cut-off value was determined to be $100 \mathrm{pg} / \mathrm{ml}$ (specificity, 45.93\%; sensitivity, 68.8\%). ROC, receiver operating characteristic; BNP, brain natriuretic peptide; AUC, area under curve.

are present in human coronary arteries (22) and are associated with the extent and severity of coronary atherosclerotic lesions (23). The observations of the present study revealed a similar correlation; the proportion of patients with myocardial infarction was significantly higher in the BNP $>100 \mathrm{pg} / \mathrm{ml}$ group as compared with the $\mathrm{BNP} \leq 100 \mathrm{pg} / \mathrm{ml}$ group $(\mathrm{P}=0.039)$. Ischemia per se may function as a stimulus for the release of BNP and NT-proBNP (24). Overactivity of the sympathetic nervous system in the left ventricle appears to be an important mechanism for the induction of elevated BNP levels in chronic ischemic HF (4). BNP gene expression levels are upregulated in 
Table II. Correlation between the $\log$ BNP levels and the incidence of compound endpoint events in all the patients.

\begin{tabular}{lccr}
\hline & \multicolumn{2}{c}{ Compound endpoint events, $\mathrm{r}$} \\
\cline { 2 - 3 } & Yes & No & Total \\
\hline $\mathrm{BNP}>100 \mathrm{pg} / \mathrm{ml}$ & 193 & 322 & 515 \\
$\mathrm{BNP} \leq 100 \mathrm{pg} / \mathrm{ml}$ & 143 & 757 & 900 \\
Total & 336 & 1079 & 1415 \\
\hline
\end{tabular}

BNP, brain natriuretic peptide.

Table III. Correlation between the $\log$ BNP levels and the incidence of compound endpoint events in the patients with diastolic dysfunction.

\begin{tabular}{lccc}
\hline & \multicolumn{2}{c}{ Compound endpoint events, $\mathrm{n}$} \\
\cline { 2 - 3 } & Yes & No & Total \\
\hline $\mathrm{BNP}>100 \mathrm{pg} / \mathrm{ml}$ & 86 & 146 & 232 \\
$\mathrm{BNP} \leq 100 \mathrm{pg} / \mathrm{ml}$ & 39 & 124 & 163 \\
Total & 125 & 270 & 395 \\
\hline
\end{tabular}

BNP, brain natriuretic peptide.

the ventricular wall by acute myocardial hypoxia, resulting in augmented plasma concentrations of $\operatorname{BNP}$ and proBNP $(25,26)$.

NT-proBNP is independent of invasive measurements of LV function and the severity of coronary artery disease (20). The prognostic importance of BNP and NT-proBNP has been extensively studied in patients with $\mathrm{HF}$, as well as in patients with acute coronary syndromes, with both markers having been demonstrated to be strong and independent predictors of morbidity and all-cause mortality $(20,27,28)$. The predictors were also evident in the subgroup of patients with a LVEF of $>60 \%$ and in patients with diabetes mellitus (29). A previous study (20) demonstrated that measuring NT-proBNP levels immediately prior to coronary angiography in patients with stable coronary heart disease provided prognostic information on all-cause mortality. The present study also demonstrated the same prognostic value. The incidence of cardiovascular mortality, readmission due to cardiovascular disease or mortality through other causes was significantly higher in the $\mathrm{BNP}>100 \mathrm{pg} / \mathrm{ml}$ group than in the BNP $\leq 100 \mathrm{pg} / \mathrm{ml}$ group. Kaplan-Meier analysis was performed to predict the survival times of the patients and the results indicated that the survival times were longer in the BNP $\leq 100 \mathrm{pg} / \mathrm{ml}$ group than in the BNP $>100 \mathrm{pg} / \mathrm{ml}$ group. The results also demonstrated a negative correlation between the $\log \mathrm{BNP}$ levels and the survival times of patients with cardiovascular disease, with survival times decreasing as the BNP levels increased. A plasma BNP level of $100 \mathrm{pg} / \mathrm{ml}$ was selected as a cut-off value for the prediction of cardiovascular morbidity and all-cause mortality, with a sensitivity of $57.44 \%$ and a specificity of $70.16 \%$ in all patients. BNP (or NT-proBNP) has been shown to have high negative predictive values as a single test (30). The observations of the present study revealed a similar outcome. The subjects of the present study included inpatients with various types of disease, including hypertension, diabetes, dyslipidemia, renal dysfunction and myocardial infarction. Therefore, this study demonstrates that the BNP level is correlated to the prediction of most cardiovascular diseases, not only one or several specific diseases. Thus, the application of BNP is wider than previously considered.

A previous study demonstrated that $40-50 \%$ of individuals with $\mathrm{HF}$ have a normal ejection fraction, and diastolic dysfunction is the presumed cause of diastolic HF (DHF) (31). Since abnormalities in diastolic function may not always produce symptoms of HF, the conditions are often missed and patients are predisposed to symptomatic HF due to the delay in treatment (31). Furthermore, the prognosis of patients suffering from DHF is as ominous as that of patients suffering from systolic HF. Diastolic dysfunction without symptoms (preclinical diastolic dysfunction) is common and is independently predictive of the future development of HF and cardiac mortality (32). Early diagnosis of LV diastolic dysfunction in an initial phase enables the start of effective treatment, which functions by stopping the progress of the disease and delaying the development of symptomatic HF (33). Analysis of the diastole by means of echocardiography, using Doppler measurements of transmitral and pulmonary vein blood flow velocities and tissue Doppler imaging, is widely accepted for clinical purposes (34). However, this type of assessment is expensive as it requires complex equipment, time-consuming as it involves the analysis of numerous variables and difficult as it must be performed by a skilled and trained operator (35). Thus, a simple and objective method to quantify diastole function with high sensitivity and specificity is required. An association between the levels of BNP and the indexes of diastolic function has been described in patients with reduced LVEF and in those with preserved LVEF (36). A previous study has shown that estimating BNP levels may be accepted as a fast and reliable blood test for the diagnosis of asymptomatic diastolic dysfunction. The BNP test may be used for the prediction of asymptomatic diastolic dysfunction in patients with hypertension (7). In addition, BNP levels may be used for the repeat evaluation of an occult LV dysfunction in patients who are periodically assessed for diabetic complications (8). Thus, BNP may be used as an adjunctive, reliable and objective method of estimating cardiac dysfunction in HCM (9). Measurement of BNP levels is simple and noninvasive, and can be easily and rapidly conducted in emergency departments to guide therapy, follow the response to therapy and predict the exercise capacity of patients (10). The observations of the present study indicated that the prognoses of patients with higher BNP levels were worse compared with those with lower BNP levels. A negative correlation between the levels of BNP and the survival times was identified in $395 \mathrm{HF}$ patients with RLVSF; survival times of the HF patients with RLVSF decreased with increasing BNP levels. Furthermore, the predictive utility of plasma BNP levels in HF patients with RLVSF for determining the incidence of compound clinical endpoints was also demonstrated. Morbidity and mortality rates from cardiovascular diseases are increased in patients with high plasma BNP levels. However, a plasma BNP level cut-off value of $100 \mathrm{pg} / \mathrm{ml}$ may be used for the prediction 
of cardiovascular morbidity and all-cause mortality, with a sensitivity of $68.8 \%$ and a specificity of $45.93 \%$ in HF patients with RLVSF. The predictive utility of plasma BNP levels in HF patients with RLVSF is lower than in all the patients.

BNP has been shown to have a higher sensitivity (85 vs. 63\%) and positive predictive value (69 vs 55\%) than NT-proBNP. The negative predictive values of BNP and NT-proBNP were similar (70 and $71 \%$, respectively) (37). The level of BNP appears to have a higher sensitivity and higher positive predictive value for the accurate diagnosis of severe LVSD than the level of NT-proBNP (38). The plasma half-life of BNP in humans is $20 \mathrm{~min}$, while the circulating half-life of NT-proBNP is $120 \mathrm{~min}$ (38). Therefore, BNP levels may used to assess the current severity of LV dysfunction, guide therapy and follow the immediate response to therapy. However, NT-proBNP is unable to this since it has an assessment lag of $\sim 10 \mathrm{~h}$. Clearance of BNP is hypothesized to occur via two main mechanisms: Binding to clearance receptors and enzymatic degradation by the enzyme neutral endopeptidase (39). Clearance of NT-proBNP occurs predominantly via the kidney, thus, in patients with mild renal dysfunction, utility of diagnosis is seriously affected $(40,41)$. Approximately $29 \%$ of HF patients have renal failure (42). BNP levels are a more useful diagnostic indicator for cardiogenic pulmonary edema than proBNP in patients aged $\geq 65$ years (40). The estimated glomerular filtration rate has independent effects on the plasma BNP and NT-proBNP concentrations in patients with chronic kidney disease. However, NT-proBNP appears to be affected more than BNP by declining kidney function (43). Therefore, in the present study, the use of plasma BNP levels may have produced reliable, accurate and effective results.

There are several relevant limitations of the present study. Firstly, the number of patients in the study was small and the follow-up period was relatively short. Further studies with a larger number of patients that are conducted over a longer time period are required to assess the predictive value of BNP levels in patients with cardiovascular-related disease, particularly in patients with RLVSF. Secondly, the echocardiographic parameters should be interpreted with caution as the ejection fraction may be affected by different sections and atrial fibrillation. Further studies with myocardial perfusion imaging are required to calculate the LVEF, which is likely to provide more precise results. Thirdly, the sensitivity and specificity values for predicting the utility of plasma BNP levels in determining the incidence of compound clinical endpoints are not very high for either groups of patients. A combination of NT-BNP (or BNP) with LVEF has been shown to substantially improve the risk stratification for mortality, HF and new ischemic events (44).

In conclusion, the prognoses were worse for patients with higher levels of BNP. Furthermore, a significant correlation was observed between BNP levels and survival times in HF patients with RLVSF. BNP can predict the prognosis of patients with cardiovascular disease, particularly in HF patients with RLVSF.

\section{References}

1. Epshteyn V, Morrison K, Krishnaswamy P, et al: Utility of B-type natriuretic peptide (BNP) as a screen for left ventricular dysfunction in patients with diabetes. Diabetes Care 26: 2081-2087, 2003.
2. Magnusson M, Melander O, Israelsson B, et al: Elevated plasma levels of NT-proBNP in patients without overt cardiovascular disease. Diabetes Care 27: 1929-1935, 2004.

3. Kremastinos DT, Tsiapras DP, Kostopoulou AG, et al: NT-proBNP levels and diastolic dysfunction in beta-thalassaemia major patients. Eur J Heart Fail 9: 531-536, 2007.

4. Sakata K, Iida K, Mochiduki N and Nakaya Y: Brain natriuretic peptide (BNP) level is closely related to the extent of left ventricular sympathetic overactivity in chronic ischemic heart failure. Intern Med 48: 393-400, 2009.

5. McKie PM, Rodeheffer RJ, Cataliotti A, et al: Amino-terminal pro-B-type natriuretic peptide and B-type natriuretic peptide: biomarkers for mortality in a large community-based cohort free of heart failure. Hypertension 47: 874-880, 2006.

6. Krittayaphong R, Boonyasirinant T, Saiviroonporn $\mathrm{P}$, et al: Correlation between NT-pro BNP levels and left ventricular wall stress, sphericity index and extent of myocardial damage: a magnetic resonance imaging study. J Card Fail 14: 687-694, 2008.

7. Karaca II, Gülcü E, Yavuzkir M, et al: B-type natriuretic peptide level in the diagnosis of asymptomatic diastolic dysfunction. Anadolu Kardiyol Derg 7: 262-267, 2007.

8. Kremastinos DT, Hamodraka E, Parissis J, et al: Predictive value of B-type natriuretic peptides in detecting latent left ventricular diastolic dysfunction in beta-thalassemia major. Am Heart J 159: 68-74, 2010.

9. Panou FK, Kotseroglou VK, Lakoumentas JA, et al: Significance of brain natriuretic peptide in the evaluation of symptoms and the degree of left ventricular diastolic dysfunction in patients with hypertrophic cardiomyopathy. Hellenic J Cardiol 47: 344-351, 2006.

10. Eroglu S, Yildirir A, Bozbas H, et al: Brain natriuretic peptide levels and cardiac functional capacity in patients with dyspnea and isolated diastolic dysfunction. Int Heart J 48: 97-106, 2007.

11. Romano S, di Mauro M, Fratini S, et al: Serial BNP assay in monitoring exercise tolerance in patients with diastolic dysfunction. Int J Cardiol 147: 312-313, 2011.

12. Hunt SA, Abraham WT, Chin MH, et al: ACC/AHA 2005 Guideline Update for the Diagnosis and Management of Chronic Heart Failure in the Adult: a report of the American College of Cardiology/American Heart Association Task Force on Practice Guidelines (Writing Committee to Update the 2001 Guidelines for the Evaluation and Management of Heart Failure): developed in collaboration with the American College of Chest Physicians and the International Society for Heart and Lung Transplantation: endorsed by the Heart Rhythm Society. Circulation 112: e154-e235, 2005.

13. Teicholz LE, Kreulen T, Herman MV and Gorlin R: Problems in echocardiographic volume determinations: echocardiographic-angiographic correlations in the presence of absence of asynergy. Am J Cardiol 37: 7-11, 1976.

14. Speranza L, Franceschelli S, Riccioni G, et al: BNP and iNOS in decompensated chronic heart failure: a linear correlation. Front Biosci (Elite Ed) 4: 1255-1262, 2012.

15. He Q, Wu G and Lapointe MC: Isoproterenol and cAMP regulation of the human brain natriuretic peptide gene involves Src and Rac. Am J Physiol Endocrinol Metab 278: E1115-E1123, 2000.

16. Suo M, Hautala N, Földes G, et al: Posttranscriptional control of BNP gene expression in angiotensin II-induced hypertension. Hypertension 39: 803-808, 2002.

17. James SK, Lindahl B, Siegbahn A, et al: N-terminal pro-brain natriuretic peptide and other risk markers for the separate prediction of mortality and subsequent myocardial infarction in patients with unstable coronary artery disease: a Global Utilization of Strategies To Open occluded arteries (GUSTO)-IV substudy. Circulation 108: 275-281, 2003.

18. Morrow DA, de Lemos JA, Blazing MA, et al; Investigators: Prognostic value of serial B-type natriuretic peptide testing during follow-up of patients with unstable coronary artery disease. JAMA 294: 2866-2871, 2005

19. Morrow DA, de Lemos JA, Sabatine MS, et al: Evaluation of B-type natriuretic peptide for risk assessment in unstable angina/non-ST-elevation myocardial infarction: B-type natriuretic peptide and prognosis in TACTICS-TIMI 18. J Am Coll Cardiol 41: 1264-1272, 2003.

20. Ceriani L and Giovanella L: Cardiac natriuretic peptides after myocardial infarction: relationship with infarct size, left ventricular function and remodelling assessed by 99mTc-sestamibi gated-single photon emission tomography. Clin Chem Lab Med 45: 226-231, 2007. 
21. Kragelund C, Grønning B, Køber L, et al: N-terminal pro-B-type natriuretic peptide and long-term mortality in stable coronary heart disease. N Engl J Med 352: 666-675, 2005.

22. Barbosa MM, Nunes Mdo C, Castro LR, et al: Correlation between NT-pro BNP levels and early mitral annulus velocity (E') in patients with non-ST-segment elevation acute coronary syndrome. Echocardiography 25: 353-359, 2008.

23. Casco VH, Veinot JP, Kuroski de Bold ML, et al: Natriuretic peptide system gene expression in human coronary arteries. J Histochem Cytochem 50: 799-809, 2002.

24. Weber M, Dill T, Arnold R et al: N-terminal B-type natriuretic peptide predicts extent of coronary artery disease and ischemia in patients with stable angina pectoris. Am Heart J 148: 612-620, 2004.

25. Omland T: B-type natriuretic peptides: prognostic markers in stable coronary artery disease. Expert Rev Mol Diagn 8: 217-225, 2008.

26. Goetze JP, Christoffersen C, Perko M, et al: Increased cardiac BNP expression associated with myocardial ischemia. FASEB J 17: 1105-1107, 2003.

27. Goetze JP, Gore A, Møller CH, et al: Acute myocardial hypoxia increases BNP gene expression. FASEB J 18: 1928-1930, 2004.

28. Omland T, Persson A, Ng L, et al: N-terminal pro-B-type natriuretic peptide and long-term mortality in acute coronary syndromes. Circulation 106: 2913-2918, 2002.

29. de Lemos JA, Morrow DA, Bentley JH, et al: The prognostic value of B-type natriuretic peptide in patients with acute coronary syndromes. N Engl J Med 345: 1014-1021, 2001.

30. Kragelund C, Gustafsson I, Omland T, et al: Prognostic value of $\mathrm{NH}_{2}$-terminal pro B-type natriuretic peptide in patients with diabetes and stable coronary heart disease. Diabetes Care 29: 1411-1413, 2006.

31. Kelder JC, Rutten FH and Hoes AW: Clinically relevant diagnostic research in primary care: the example of B-type natriuretic peptides in the detection of heart failure. Fam Pract 26: 69-74, 2009.

32. Redfield MM, Jacobsen SJ, Burnett JC Jr, et al: Burden of systolic and diastolic ventricular dysfunction in the community: appreciating the scope of the heart failure epidemic. JAMA 289: 194-202, 2003

33. Shimabukuro M, Higa N, Oshiro Y, et al: Diagnostic utility of brain-natriuretic peptide for left ventricular diastolic dysfunction in asymptomatic type 2 diabetic patients. Diabetes Obes Metab 9: 323-329, 2007.

34. Görmüş U, Ozmen D, Ozmen B, et al: Serum N-terminal-pro-brain natriuretic peptide (NT-pro-BNP) and homocysteine levels in type 2 diabetic patients with asymptomatic left ventricular diastolic dysfunction. Diabetes Res Clin Pract 87: 51-56, 2010.
35. Metra M, Ponikowski P, Dickstein K, et al; Heart Failure Association of the European Society of Cardiology: Advanced chronic heart failure: A position statement from the Study Group on Advanced Heart Failure of the Heart Failure Association of the European Society of Cardiology. Eur J Heart Fail 9: 684-694, 2007.

36. Nagueh SF, Appleton CP, Gillebert TC, et al: Recommendations for the evaluation of left ventricular diastolic function by echocardiography. J Am Soc Echocardiogr 22: 107-133, 2009.

37. Grewal J, McKelvie R, Lonn E, et al: BNP and NT-proBNP predict echocardiographic severity of diastolic dysfunction. Eur J Heart Fail 10: 252-259, 2008.

38. Kotaska K, Popelova J, Tiserova M, et al: NT-proBNP and BNP values in cardiac patients with different degree of left ventricular systolic dysfunction. Biomed Pap Med Fac Univ Palacky Olomouc Czech Repub 150: 125-130, 2006

39. Mair J, Hammerer-Lercher A and Puschendorf B: The impact of cardiac natriuretic peptide determination on the diagnosis and management of heart failure. Clin Chem Lab Med 39: 571-588, 2001.

40. Ruskoaho H: Cardiac hormones as diagnostic tools in heart failure. Endor Rev 24: 341-356, 2003.

41. Ray P, Arthaud M, Birolleau S, et al: Comparison of brain natriuretic peptide and probrain natriuretic peptide in the diagnosis of cardiogenic pulmonary edema in patients aged 65 and older. $\mathrm{J}$ Am Geriatr Soc 53: 643-648, 2005.

42. Sykes E, Karcher RE, Eisenstadt J, et al: Analytical relationships among Biosite, Bayer, and Roche methods for BNP and NT-proBNP. Am J Clin Pathol 123: 584-590, 2005.

43. Fonarow GC; ADHERE Scientific Advisory Committee: The Acute Decompensated Heart Failure National Registry (ADHERE): opportunities to improve care of patients hospitalized with acute decompensated heart failure. Rev Cardiovasc Med 4 (Suppl 7): S21-S30, 2003.

44. Vickery S, Price CP, John RI, et al: B-type natriuretic peptide (BNP) and amino-terminal proBNP in patients with CKD: relationship to renal function and left ventricular hypertrophy. Am J Kidney Dis 46: 610-620, 2005.

45. Richards AM, Nicholls MG, Espiner EA, et al: B-type natriuretic peptides and ejection fraction for prognosis after myocardial infarction. Circulation 107: 2786-2792, 2003. 